\title{
Association Between Urate-lowering Therapies and Cognitive Decline in Community-dwelling Older Adults: a Post-hoc Analysis of the MAPT Study.
}

Luc MOLET-BENHAMOU ( $\sim$ lucmolben@gmail.com )

Centre Hospitalier Universitaire de Toulouse

Kelly VIRECOULON GIUDICI

Centre Hospitalier Universitaire de Toulouse

Philipe BARRETO

Centre Hospitalier Universitaire de Toulouse

Christelle CANTET

Centre Hospitalier Universitaire de Toulouse

Yves ROLLAND

Centre Hospitalier Universitaire de Toulouse

\section{Research Article}

Keywords: allopurinol, Alzheimer's disease, cognitive decline, composite cognitive score, dementia, febuxostat, gout, gouty arthritis, inflammaging, monosodium urate crystal-induced arthritis, Multidomain Alzheimer Preventive Trial study, urate-lowering therapies

Posted Date: March 1st, 2022

DOI: https://doi.org/10.21203/rs.3.rs-699328/v2

License: (c) (i) This work is licensed under a Creative Commons Attribution 4.0 International License. Read Full License 


\section{Abstract}

\section{Introduction}

Long-term use of urate-lowering therapies (ULT) may reduce inflammaging and thus prevent cognitive decline during aging. This article examined the association between long-term use of ULT and cognitive decline among communitydwelling older adults with spontaneous memory complaints.

\section{Material and methods}

We performed a secondary observational analysis using data of 1,673 participants $\geq 70$ years old from the Multidomain Alzheimer Preventive Trial (MAPT Study), a randomized controlled trial assessing the effect of a multidomain intervention, the administration of polyunsaturated fatty acids (PUFA), both, or placebo on cognitive decline. We compared cognitive decline during the 5-year follow-up between three groups according to ULT use: participants treated with ULT during at least $75 \%$ of the study period (PT $\geq 75 ; n=51)$, less than $75 \%(P T<75 ; n=31)$, and non-treated participants (PNT; $n=1,591$ ). Cognitive function (measured by a composite score) was assessed at baseline, 6 months and every year for 5 years. Linear mixed models were performed and adjusted for age, sex, body mass index (BMI), diagnosis of arterial hypertension or diabetes, baseline composite cognitive score, and MAPT intervention groups.

\section{Results}

After the 5-year follow-up, only non-treated participants presented a significant decline in the cognitive composite score (mean change $-0.173,95 \% \mathrm{Cl}-0.212$ to $-0.135 ; \mathrm{p}<0.0001$ ). However, there were no differences in change of the composite cognitive score between groups (adjusted between-group difference for PNT vs. PT<75: $0.089,95 \% \mathrm{Cl}-0.160$ to $0.338, p=0.484$; PNT vs. PT $\geq 75: 0.174,95 \% \mathrm{Cl}-0.042$ to $0.391, p=0.115$ ).

\section{Conclusion}

Use of ULT was not associated with reduced cognitive decline over a 5-year follow-up among community-dwelling older adults at risk of dementia.

\section{Introduction}

Cognitive decline is a rising issue as the population of older adults keeps increasing. Neuroinflammation involving oxidative stress ${ }^{1}$ is reported to play a major role ${ }^{2}$ on cognitive impairment.

The fact that uric acid has anti-oxidant properties and has the ability to reduce systemic inflammation has raised the hypothesis that hyperuricemia or gout may be protective against dementia, Alzheimer's disease (AD) and cognitive decline ${ }^{3,4}$. Recent epidemiological studies that investigated the association between serum uric acid level and AD were mainly cross-sectional and are somewhat conflicting ${ }^{5}$. However, it was also reported in a large cohort that gout was independently associated with a $15 \%$ higher risk of incident dementia among older adults ${ }^{6}$.

Publications have paradoxically reported that urate-lowering therapies (ULT) may decrease the systemic inflammation and reduce the production of oxidative species ${ }^{7,8}$. ULT may also reverse endothelial dysfunction and thus have cardioprotective benefits. Neuroprotective effects of ULT both in animal studies ${ }^{9}$ and human cohorts ${ }^{10}$ have been reported. Singh et al. ${ }^{11}$ reported a dose-related reduction in the risk of dementia among people older than 65 years treated with ULT. 
These studies remain scarce and controversial. Some of their limitations were the lack of evaluation criteria of cognitive decline $\mathrm{1}^{12,13,14,15}$ and short-term follow-ups. Furthermore, analyses were based on general data of the health administrative database. In addition, participants investigated in these studies were not at higher risk of cognitive decline or AD, thus limiting the possibility of studying the link between cognitive decline and ULT.

The aim of the present study was to investigate the association between long-term ULT and cognitive decline in a sample of community-dwelling older adults with subjective memory complaints over a five-year follow-up.

\section{Materials And Methods}

\section{Study population}

To evaluate a potential association between ULT and cognitive decline, we used data from the Multidomain Alzheimer Preventive Trial (MAPT) Study. The design of MAPT has been previously described in details elsewhere ${ }^{16}$. Briefly, the MAPT study is a randomized clinical trial performed in 13 centers in France and Monaco assessing cognitive outcomes in patients at risk of cognitive decline, including subjects older than 70 years with the following criteria: spontaneous memory complaint, limitations in one Instrumental Activity of Daily Living (IADL) or slow gait speed ( $\leq$ $0.8 \mathrm{~m} / \mathrm{s}$ ). Participants were assigned to different interventions for 3 years, and then followed for additional 2 years. Interventions comprised supplementation with omega 3 polyunsaturated fatty acids, multidomain intervention (covering cognitive training, physical activity and nutrition counselling), or both. These three groups were compared to a placebo group. Follow-up visits were scheduled at 6 and 12 months and then every year to assess outcomes, diseases and corresponding treatments. Participants were invited to come with all their treatment orders.

In summary, no statistically significant difference has been noted in the evolution of the main primary outcome (a composite cognitive score) between the four groups at 3 years, after controlling for multiple comparisons ${ }^{17}$.

From the total of 1,679 participants originally analyzed in the MAPT Study, those with information on ULT were included in the present study $(n=1,673)$.

\section{Ethical consent}

All participants were recruited by the investigating physicians, after obtaining their written informed consent. The trial protocol was approved by the French Ethical Committee located in Toulouse, France (CPP SOOM II) and was authorized by the French Health Authority in 2007. All methods were performed in accordance with the relevant guidelines and regulations.

\section{ULT data collection}

The use of ULT (Anatomic Therapeutic Chemical code: M04AA01 for allopurinol or M04AA03 for febuxostat) were recorded at each visit. Patients treated by uricosuric or uricolytic drugs or treated with colchicine were not included in the treated groups, given the different mechanism of action of these drugs ${ }^{18}$ (uricosuric drugs including benzbromarone, sulfinpyrazone, and probenecid block renal tubular urate reabsorption and are second-line therapies for gout).

Three different groups were defined according to the use of urate-lowering medication, as follows: participants treated with ULT during at least $75 \%$ of the study 5 -year period (PT $\geq 75 ; n=51$ ), participants treated with ULT for less than $75 \%$ of the study (PT < 75; $n=31$ ), and participants never treated with ULT during the study (PNT; $n=1,591)$. Among 
those treated with ULT, 14 subjects had no treatment start date; we then considered that these subjects were treated since baseline or earlier.

\section{Outcome measure}

Cognitive function was assessed by a composite cognitive score combining the mean Z-score of four tests exploring: (i) episodic memory (Free and Cued Selective Reminding test: sum of the free and total (free + cued) recalls), (ii) orientation (10 orientation items from the Mini Mental State Examination - MMSE test), and (iii) executive function (WAIS Digit Symbol Substitution Test, and Category Fluency Test).

Cognitive assessments were performed at inclusion, every six months during the first year and every year until the fifth year of follow-up.

\section{Confounding variables}

To take into account potential confounding factors, the following variables were considered: age, sex, body mass index $\left(\mathrm{BMI}=\right.$ weight $(\mathrm{kg}) /$ height $\left.(\mathrm{m})^{2}\right)$, diagnosis of arterial hypertension or diabetes, allocation to MAPT intervention groups.

\section{Statistical analysis}

To describe the population, means and standard deviation for quantitative variables, and frequencies and percentage for qualitative variables were used. To compare the characteristics at baseline between the three urate-lowering treatment groups (PT $\geq 75, \mathrm{PT}<75$ and PNT), the Chi-square test or Fisher's exact tests (in the case of expected frequencies $<5$ ) were used for the qualitative variables, and Fisher test or the non-parametric Kruskal-Wallis test were used for quantitative variables.

To study the change of the composite cognitive score over time according to the ULT groups, mixed linear models were performed to take into account the correlated structure of the data (intra-center and intra-subject correlation, with subjects nested into the center). We included as random effects a random center intercept, a random subject intercept, and a random subject slope.

This model was performed without adjustment with the following fixed effects: time, ULT groups and time $\times$ group interaction. An adjusted model was then performed by adding the above-mentioned confounding variables as fixed effects. The statistically significant difference at baseline in the composite cognitive score according to the treatment group was also considered in the mixed model. Time was treated as a continuous variable, with a cubic trajectory since the terms time ${ }^{2}$ and time ${ }^{3}$ were significant.

All analyses were performed using SAS software version 9.4 (SAS Institute Inc., Cary, NC), and results were considered significant if $p<0.05$.

\section{Results}

Among the 1,673 participants of the study, 1,591 were not treated with ULT (PNT, 95\%), whereas 82 were treated with ULT, with the following distribution: 31 in the group PT $<75$ (2\%) and 51 in the group PT $\geq 75$ (3\%). Baseline characteristics of the groups are reported in Table 1. In summary, both PT $<75$ and PT $\geq 75$ groups presented higher BMI, were older, more often hypertensive and more frequently male than the PNT group. Diabetes was significantly more prevalent in the PT $\geq 75$ group compared to the other groups. The composite cognitive score at baseline were statistically different among the groups $(0.00, S D=0.67$ for $\mathrm{PNT} ; 0.30, \mathrm{SD}=0.56$ for $\mathrm{PT}<75 ;-0.12, \mathrm{SD}=0.76$ for $\mathrm{PT} \geq$ $75 ; p=0.019)$. Other parameters such as the inclusion criteria, allocation to MAPT intervention group, level of 
education or the presence of the apolipoprotein E4 (APOE4) mutation, were not differently distributed between the groups. 
Table 1

Participants' characteristics at baseline.

\begin{tabular}{|c|c|c|c|c|c|c|c|c|c|}
\hline \multirow[b]{2}{*}{$\begin{array}{l}\text { Parameter at } \\
\text { baseline }\end{array}$} & \multicolumn{2}{|c|}{$\begin{array}{l}\text { Total population( } \mathrm{N} \\
=1673)\end{array}$} & \multicolumn{2}{|c|}{ PNT $(n=1591)$} & \multicolumn{2}{|c|}{$\mathrm{PT}<75(\mathrm{n}=31)$} & \multicolumn{2}{|c|}{ PT $\geq 75(n=51)$} & \multirow[b]{2}{*}{$\begin{array}{l}\mathrm{p}- \\
\text { value } \\
\ddagger\end{array}$} \\
\hline & $\mathrm{N}$ & $\begin{array}{l}\text { Mean (SD) } \\
\text { or } \\
\text { percentage }\end{array}$ & $\mathrm{N}$ & $\begin{array}{l}\text { Mean (SD) } \\
\text { or } \\
\text { percentage }\end{array}$ & $\mathrm{N}$ & $\begin{array}{l}\text { Mean (SD) } \\
\text { or } \\
\text { percentage }\end{array}$ & $\mathrm{N}$ & $\begin{array}{l}\text { Mean (SD) } \\
\text { or } \\
\text { percentage }\end{array}$ & \\
\hline \multicolumn{10}{|l|}{ Demographic data } \\
\hline Age (years) & & $\begin{array}{l}75.33 \\
(4.42)\end{array}$ & & $\begin{array}{l}75.26 \\
(4.38)\end{array}$ & & $\begin{array}{l}77.13 \\
(5.36)\end{array}$ & & $\begin{array}{l}76.43 \\
(4.74)\end{array}$ & 0.03 \\
\hline Sex (women) & 1085 & $64.85 \%$ & 1062 & $66.75 \%$ & 13 & $41.94 \%$ & 10 & $19.61 \%$ & $\begin{array}{l}<.0001 \\
0.00\end{array}$ \\
\hline $\begin{array}{l}\text { Education level } \\
(\mathrm{N}=1638) *\end{array}$ & 0.68 & & & & & & & & \\
\hline $\begin{array}{l}\text { No diploma or } \\
\text { primary school } \\
\text { certificate }\end{array}$ & 369 & $22.53 \%$ & 355 & $22.80 \%$ & 4 & $12.90 \%$ & 10 & $20.00 \%$ & \\
\hline $\begin{array}{l}\text { Secondary } \\
\text { education }\end{array}$ & 553 & $33.76 \%$ & 528 & $33.91 \%$ & 10 & $32.26 \%$ & 15 & $30.00 \%$ & \\
\hline $\begin{array}{l}\text { High school } \\
\text { diploma }\end{array}$ & 242 & $14.77 \%$ & 230 & $14.77 \%$ & 4 & $12.90 \%$ & 8 & $16.00 \%$ & \\
\hline University level & 474 & $28.94 \%$ & 444 & $28.52 \%$ & 13 & $41.94 \%$ & 17 & $34.00 \%$ & \\
\hline \multicolumn{10}{|l|}{ Clinical data } \\
\hline $\begin{array}{l}\text { Arterial } \\
\text { hypertension }\end{array}$ & 899 & $53.74 \%$ & 830 & $52.17 \%$ & 28 & $90.32 \%$ & 41 & $80.39 \%$ & $\begin{array}{l}< \\
0.0001\end{array}$ \\
\hline Diabetes & 160 & $9.56 \%$ & 143 & $8.99 \%$ & 2 & $6.45 \%$ & 15 & $29.41 \%$ & 0.0001 \\
\hline $\operatorname{BMI}(\mathrm{N}=1666)^{\star}$ & & $\begin{array}{l}26.11 \\
(4.08)\end{array}$ & & $\begin{array}{l}26.00 \\
(4.06)\end{array}$ & & $\begin{array}{l}27.40 \\
(3.97)\end{array}$ & & $\begin{array}{l}28.96 \\
(3.48)\end{array}$ & $\begin{array}{l}<.0001 \\
0.00\end{array}$ \\
\hline $\begin{array}{l}\text { Fried score }>0 \\
(\mathrm{~N}=1603)^{\star}\end{array}$ & 738 & $46.04 \%$ & 694 & $45.45 \%$ & 17 & $56.67 \%$ & 27 & $58.70 \%$ & 0.10 \\
\hline $\begin{array}{l}\text { ApoE4 carriers } \\
(\mathrm{N}=1298) *\end{array}$ & 299 & $23.04 \%$ & 286 & $23.18 \%$ & 5 & $20.83 \%$ & 8 & $20.00 \%$ & 0.87 \\
\hline $\begin{array}{l}\text { Composite } \\
\text { cognitive score }\end{array}$ & 1673 & $0.00(0.67)$ & 1591 & $0.00(0.67)$ & 31 & $0.30(0.56)$ & 51 & $\begin{array}{l}-0.12 \\
(0.76)\end{array}$ & 0.0185 \\
\hline \multicolumn{10}{|l|}{ Inclusion criteria } \\
\hline Gait speed (m/s) & & $1.09(0.26)$ & & $1.09(0.26)$ & & $1.09(0.25)$ & & $1.12(0.26)$ & 0.63 \\
\hline $\begin{array}{l}\text { Memory } \\
\text { complaint }\end{array}$ & 1659 & $99.16 \%$ & 1578 & $99.18 \%$ & 30 & $96.77 \%$ & 51 & $100.00 \%$ & 0.28 \\
\hline $\mid A D L<8$ & 184 & $11.00 \%$ & 176 & $11.06 \%$ & 2 & $6.45 \%$ & 6 & $11.76 \%$ & 0.78 \\
\hline \multicolumn{10}{|l|}{ Imaging data } \\
\hline $\begin{array}{l}\text { Florbétapir-PET } \\
>0(\mathrm{~N}=270)^{*}\end{array}$ & 103 & $38.15 \%$ & 97 & $37.89 \%$ & 3 & $42.86 \%$ & 3 & $42.86 \%$ & 1.00 \\
\hline
\end{tabular}




\begin{tabular}{|c|c|c|c|c|c|c|c|c|c|}
\hline & \multicolumn{2}{|c|}{$\begin{array}{l}\text { Total population }(\mathrm{N} \\
=1673)\end{array}$} & \multicolumn{2}{|c|}{ PNT (n = 1591) } & \multicolumn{2}{|c|}{ PT $<75(n=31)$} & \multicolumn{3}{|c|}{$P T \geq 75(n=51)$} \\
\hline Intervention group & & & & & & & & & 0.68 \\
\hline $\begin{array}{l}\text { Omega } 3 \\
\text { supplementation } \\
+ \text { Multidomain } \\
\text { intervention }\end{array}$ & 414 & $24.75 \%$ & 390 & $24.51 \%$ & 9 & $29.03 \%$ & 15 & $29.41 \%$ & \\
\hline $\begin{array}{l}\text { Omega } 3 \\
\text { supplementation } \\
\text { only }\end{array}$ & 419 & $25.04 \%$ & 399 & $25.08 \%$ & 10 & $32.26 \%$ & 10 & $19.61 \%$ & \\
\hline $\begin{array}{l}\text { Multidomain } \\
\text { intervention + } \\
\text { placebo }\end{array}$ & 420 & $25.10 \%$ & 400 & $25.14 \%$ & 8 & $25.81 \%$ & 12 & $23.53 \%$ & \\
\hline Placebo only & 420 & $25.10 \%$ & 402 & $25.27 \%$ & 4 & $12.90 \%$ & 14 & $27.45 \%$ & \\
\hline \multicolumn{10}{|c|}{ *Number of subjects with available data } \\
\hline \multicolumn{10}{|c|}{$\begin{array}{l}\text { ¥Statistical tests are comparing the three groups } \\
\text { PNT, PT }<75 \text { and PT } \geq 75\end{array}$} \\
\hline \multicolumn{10}{|c|}{$\begin{array}{l}\text { ApoE4: apolipoprotein E4; BMI : body mass index; PNT : participants not treated; PT < } 75 \text { :participants treated less } \\
\text { than } 75 \% \text { of the study follow-up; PT } \geq 75 \text { :participants treated more than } 75 \% \text { of the study follow-up; PET : positron } \\
\text { emission tomography; SD :standard deviation }\end{array}$} \\
\hline \multicolumn{10}{|c|}{ Significative values are written in bold text } \\
\hline
\end{tabular}

After the 5-year follow-up, only the PNT group presented a significant decline in the composite cognitive score (mean change $-0.173,95 \% \mathrm{Cl}-0.212$ to $-0.135, \mathrm{p}<0.0001$ ) (Fig. 1 and Table 2 ). 
Table 2

Linear mixed models presenting changes of the composite cognitive score according to urate-lowering therapies administration among community-dwelling older adults.

\begin{tabular}{|c|c|c|c|c|c|c|c|}
\hline & \multicolumn{3}{|c|}{ Estimated change from baseline } & \multicolumn{2}{|c|}{$\begin{array}{l}\text { Estimated differences in } \\
\text { change from baseline }\end{array}$} & \multicolumn{2}{|c|}{$\begin{array}{l}\text { Estimated differences in } \\
\text { change from baseline }\end{array}$} \\
\hline \multirow[t]{2}{*}{ Time } & $\begin{array}{l}\text { PNT } \\
\text { mean } \\
{[95 \% \mathrm{Cl}]} \\
\text { p-value }\end{array}$ & $\begin{array}{l}\mathrm{PT}<75 \% \\
\text { mean } \\
{[95 \% \mathrm{Cl}]} \\
\text { p-value }\end{array}$ & $\begin{array}{l}\mathrm{PT} \geq 75 \% \\
\text { mean } \\
{[95 \% \mathrm{Cl}]} \\
\text { p-value }\end{array}$ & $\begin{array}{l}\mathrm{PT}<75 \% \text { vs } \\
\mathrm{PNT} \\
\text { mean } \\
{[95 \% \mathrm{Cl}]} \\
\text { p-value }\end{array}$ & $\begin{array}{l}\mathrm{PT} \geq 75 \% \text { vs } \\
\mathrm{PNT} \\
\text { mean }[95 \% \mathrm{Cl}] \\
\text { p-value }\end{array}$ & $\begin{array}{l}\mathrm{PT}<75 \% \text { vs } \\
\mathrm{PNT} \\
\text { mean } \\
{[95 \% \mathrm{Cl}]} \\
\text { p-value }\end{array}$ & $\begin{array}{l}\mathrm{PT} \geq 75 \% \text { vs } \\
\text { PNT } \\
\text { mean }[95 \% \mathrm{Cl}] \\
\text { p-value }\end{array}$ \\
\hline & \multicolumn{5}{|c|}{ Not adjusted } & \multicolumn{2}{|l|}{ Adjusted $^{(1)}$} \\
\hline \multirow{3}{*}{$\begin{array}{l}3 \\
\text { years }\end{array}$} & -0.060 & -0.049 & 0.055 & 0.010 & 0.114 & 0.051 & 0.163 \\
\hline & $\begin{array}{l}{[-0.090 \text { to }} \\
-0.029]\end{array}$ & $\begin{array}{l}{[-0.251 \text { to }} \\
0.153]\end{array}$ & $\begin{array}{l}{[-0.115 \text { to }} \\
0.224]\end{array}$ & $\begin{array}{l}{[-0.194 \text { to }} \\
0.214]\end{array}$ & $\begin{array}{l}{[-0.058 \text { to }} \\
0.286]\end{array}$ & $\begin{array}{l}{[-0.150 \text { to }} \\
0.252]\end{array}$ & $\begin{array}{l}{[-0.010 \text { to }} \\
0.335]\end{array}$ \\
\hline & $p=0.0002$ & $p=0.633$ & $p=0.528$ & $p=0.920$ & $p=0.194$ & $p=0.617$ & $p=0.065$ \\
\hline \multirow[t]{3}{*}{$\begin{array}{l}5 \\
\text { years }\end{array}$} & -0.173 & -0.155 & -0.088 & 0.018 & 0.085 & 0.089 & 0.174 \\
\hline & $\begin{array}{l}{[-0.212 \text { to }} \\
-0.135]\end{array}$ & $\begin{array}{l}{[-0.405 \text { to }} \\
0.095]\end{array}$ & $\begin{array}{l}{[-0.300 \text { to }} \\
0.124]\end{array}$ & $\begin{array}{l}{[-0.235 \text { to }} \\
0.271]\end{array}$ & $\begin{array}{l}{[-0.130 \text { to }} \\
0.300]\end{array}$ & $\begin{array}{l}{[-0.160 \text { to }} \\
0.338]\end{array}$ & $\begin{array}{l}{[-0.042 \text { to }} \\
0.391]\end{array}$ \\
\hline & $p<0.0001$ & $p=0.223$ & $p=0.414$ & $p=0.889$ & $p=0.437$ & $p=0.484$ & $p=0.115$ \\
\hline \multicolumn{8}{|c|}{$\begin{array}{l}\text { PNT: participants not treated; PT < 75: participants treated less than } 75 \% \text { of the study follow-up; PT } \geq 75 \text { : } \\
\text { participants treated more than } 75 \% \text { of the study follow-up }\end{array}$} \\
\hline
\end{tabular}

However, no differences were observed when comparing evolution of the composite cognitive score between the treated groups and the PNT group (PT $\geq 75$ vs. PNT: $0.085,95 \% \mathrm{Cl}-0.130$ to $0.300, p=0.437 ; \mathrm{PT}<75$ vs. PNT: 0.018 , $95 \% \mathrm{Cl}-0.235$ to $0.271, \mathrm{p}=0.889$ ). Results remained similar in the adjusted models (PT $\geq 75$ vs. PNT: $0.174,95 \% \mathrm{Cl}$ -0.042 to $0.391, p=0.115 ; \mathrm{PT}<75$ vs. PNT: $0.089,95 \% \mathrm{Cl}-0.160$ to $0.338, \mathrm{p}=0.484$ ) (Table 2 ).

\section{Discussion}

Our study evaluated the evolution of a composite cognitive score in a long follow-up of 5 years between participants treated with ULT and participants not treated with ULT, in a sample of community-dwelling older adults at risk of cognitive decline. To our knowledge, this is the first study assessing the long-term association of ULT with cognitive function in a population at risk of cognitive decline. No statistically significant differences in the evolution of a composite cognitive score was observed between the participants treated with ULT (whether they were treated during a long period of time or not) and the participants not treated with ULT. 
Hyperuricemia is associated with several co-morbidities such as chronic kidney disease ${ }^{19}$, cardiovascular heart disease, arterial hypertension ${ }^{20}$, obesity and diabetes ${ }^{21}$. However, it has not been demonstrated that hyperuricemia is the cause and not just the consequence of these diseases. An important factor that may link hyperuricemia with these diseases is its deleterious effect on small vessels ${ }^{22}$. Despite having extracellular antioxidant properties, the urate acid induces endothelial dysfunction inside the cell ${ }^{23}$, and lowering uric acid concentrations has been reported to reduce cardiovascular events in patients with chronic kidney disease ${ }^{24}$. Our research are in line with a recent large systematic review and meta-analysis involving 16,000 participants, that found no significant association between serum urate levels and cognition ${ }^{25}$.

Both allopurinol and febuxostat can cross the blood-brain barrier (with a probability of $99 \%$ and $79 \%$, respectively ${ }^{26}$, calculated with the chemical absorption, distribution, metabolism, excretion, and toxicity - ADMET features of these drugs $^{27}$ ) and can directly interfere with intracerebral metabolism and neuronal cell ${ }^{28}$. These two molecules may have neuroprotective effects independently of their lowering effect of urate serum level ${ }^{29}$. Allopurinol was reported to reduce oxidative stress and proinflammatory molecules in the vessels, thus reducing vascular damages in the brain. This neuroprotective effect has been reported to be related to an inhibition of the nitrosative stress and an attenuation of microglia infiltration and astrocytes reactivation in a mouse model of cortical microinfarction ${ }^{9}$. The potential benefits of the neuroprotective effect of allopurinol have been currently investigated in a phase III clinical trial in the context of hypoxic-ischemic brain injury in neonatology ${ }^{10}$. Cerebral microinfarcts are very frequent in patients with mild cognitive decline ${ }^{30}$, vascular dementia and $A D^{31-32}$. Our research, however, did not show that ULT was associated with a protection of cognitive function (i.e., slower cognitive decline).

Our study has several strengths. Our selected population reported subjective memory complaints, a well-known condition associated with higher risk of cognitive decline ${ }^{33}$. Another strength of our study is the use of a composite cognitive score based on multiple cognitive tests to evaluate cognitive functions, which has been repeatedly validated $^{34}$. Moreover, the measures of cognitive function have been repeated at several time-points, helping us follow the different cognitive trajectories more accurately. On the other hand, some limitations should be addressed. First, this is a post-hoc observational study using data from a RCT that was not designed to test the effects of ULT on cognition. Second, the small number of subjects in the PT $<75$ and PT $\geq 75$ groups may have limited the power of the statistical analysis. Third, serum uric acid levels were not available, what impeded us of investigating their interaction with ULT. Fourth, dose-response associations could not be explored since ULT dosing was not available. Finally, although based in our clinical experience, the $75 \%$ cut-off for ULT taking was arbitrary; other cut-offs should be tested in future works.

In conclusion, this study did not find significant associations between ULT and changes in cognitive function over time in a population of older adults at risk of cognitive decline. Given the small fraction of people under ULT, larger observational prospective studies are needed to examine the associations between ULT and cognition over time. Randomized controlled trials investigating the effects of ULT on the cognitive function of patients might shed light on this topic.

\section{Abbreviations}

AD: Alzheimer's disease

ADMET: absorption, distribution, metabolism, excretion, and toxicity

APOE4: apolipoprotein E4

Page 9/14 
BMI: body mass index

IADL: Instrumental Activity of Daily Living

MAPT: Multidomain Alzheimer Preventive Trial

MMSE: Mini Mental Status Evaluation

PNT: participants not treated

PT<75: participants treated with ULT for less than $75 \%$ of the study

PT $\geq 75$ : participants treated with ULT during at least $75 \%$ of the study

SD: standard deviation

ULT: urate-lowering therapies

\section{Declarations}

\section{Ethical Approval and Consent to participate}

Not applicable.

\section{Consent for publication}

The publication was approved by the MAPT/DSA group*.

\section{Availability of supporting data}

Pr Yves Rolland \& Pr Philipe Barreto, CERPOP, UMR1295, unité mixte INSERM - Université Toulouse III Paul Sabatier have the full access to the MAPT database.

The datasets used and/or analysed during the current study available from the corresponding author on reasonable request.

\section{Competing interests}

JANSSEN-CILAG (Luc Molet-Benhamou).

\section{Author's contributions}

correction (Yves Rolland, Kelly Giudici, Philipe Barreto).

\section{Funding}

The MAPT study was supported by grants from the French Ministry of Health (PHRC 2008, 2009), University Hospital Center of Toulouse / Gérontopôle, Pierre Fabre Research Institute (manufacturer of the omega-3 supplement), ExonHit Therapeutics (biological sample collection) and Avid Radiopharmaceuticals (PET-amyloid measurement). The promotion of this study was supported by the University Hospital Center of Toulouse. The data sharing activity was supported by the Association Monegasque pour la Recherche sur la maladie d'Alzheimer (AMPA) and the UMR 1027 Unit INSERM-University of Toulouse III. The present work was performed in the context of the Inspire Program, a 
research platform supported by grants from the Region Occitanie/Pyrénées-Méditerranée (Reference number: 1901175) and the European Regional Development Fund (ERDF) (Project number: MP0022856) and received funds from Alzheimer Prevention in Occitania and Catalonia (APOC Chair of Excellence - Inspire Program).

\section{Acknowledgements}

*MAPT/DSA group

MAPT Study Group

Principal investigator: Bruno Vellas (Toulouse); Coordination: Sophie Guyonnet; Project leader: Isabelle Carrié; CRA: Lauréane Brigitte; Investigators: Catherine Faisant, Françoise Lala, Julien Delrieu, Hélène Villars; Psychologists: Emeline Combrouze, Carole Badufle, Audrey Zueras; Methodology, statistical analysis and data management: Sandrine Andrieu, Christelle Cantet, Christophe Morin; Multidomain group: Gabor Abellan Van Kan, Charlotte Dupuy, Yves Rolland (physical and nutritional components), Céline Caillaud, Pierre-Jean Ousset (cognitive component), Françoise Lala (preventive consultation) (Toulouse). The cognitive component was designed in collaboration with Sherry Willis from the University of Seattle, and Sylvie Belleville, Brigitte Gilbert and Francine Fontaine from the University of Montreal. Co-Investigators in associated centres: Jean-François Dartigues, Isabelle Marcet, Fleur Delva, Alexandra Foubert, Sandrine Cerda (Bordeaux); Marie-Noëlle-Cuffi, Corinne Costes (Castres); Olivier Rouaud, Patrick Manckoundia, Valérie Quipourt, Sophie Marilier, Evelyne Franon (Dijon); Lawrence Bories, Marie-Laure Pader, MarieFrance Basset, Bruno Lapoujade, Valérie Faure, Michael Li Yung Tong, Christine Malick-Loiseau, Evelyne CazabanCampistron (Foix); Françoise Desclaux, Colette Blatge (Lavaur); Thierry Dantoine, Cécile Laubarie-Mouret, Isabelle Saulnier, Jean-Pierre Clément, Marie-Agnès Picat, Laurence Bernard-Bourzeix, Stéphanie Willebois, Iléana Désormais, Noëlle Cardinaud (Limoges); Marc Bonnefoy, Pierre Livet, Pascale Rebaudet, Claire Gédéon, Catherine Burdet, Flavien Terracol (Lyon), Alain Pesce, Stéphanie Roth, Sylvie Chaillou, Sandrine Louchart (Monaco); Kristel Sudres, Nicolas Lebrun, Nadège Barro-Belaygues (Montauban); Jacques Touchon, Karim Bennys, Audrey Gabelle, Aurélia Romano, Lynda Touati, Cécilia Marelli, Cécile Pays (Montpellier); Philippe Robert, Franck Le Duff, Claire Gervais, Sébastien Gonfrier (Nice); Yannick Gasnier and Serge Bordes, Danièle Begorre, Christian Carpuat, Khaled Khales, Jean-François Lefebvre, Samira Misbah El Idrissi, Pierre Skolil, Jean-Pierre Salles (Tarbes). MRI group: Carole Dufouil (Bordeaux), Stéphane Lehéricy, Marie Chupin, Jean-François Mangin, Ali Bouhayia (Paris); Michèle Allard (Bordeaux); Frédéric Ricolfi (Dijon); Dominique Dubois (Foix); Marie Paule Bonceour Martel (Limoges); François Cotton (Lyon); Alain Bonafé (Montpellier); Stéphane Chanalet (Nice); Françoise Hugon (Tarbes); Fabrice Bonneville, Christophe Cognard, François Chollet (Toulouse). PET scans group: Pierre Payoux, Thierry Voisin, Julien Delrieu, Sophie Peiffer, Anne Hitzel (Toulouse); Michèle Allard (Bordeaux); Michel Zanca (Montpellier); Jacques Monteil (Limoges); Jacques Darcourt (Nice). Medico-economics group: Laurent Molinier, Hélène Derumeaux, Nadège Costa (Toulouse). Biological sample collection: Bertrand Perret, Claire Vinel, Sylvie Caspar-Bauguil (Toulouse). Safety management: Pascale Olivier-Abbal.

DSA Group: Sandrine Andrieu, Christelle Cantet, Nicola Coley.

\section{References}

1. Franceschi, C., Garagnani, P., Parini, P., Giuliani, C. \& Santoro, A. Inflammaging: a new immune-metabolic viewpoint for age-related diseases. Nature Reviews. Endocrinology 14, 576-590 (2018).

2. Butterfield, D. A. \& Halliwell, B. Oxidative stress, dysfunctional glucose metabolism and Alzheimer disease. Nature Reviews. Neuroscience 20, 148-160 (2019). 
3. Tuven, B., Soysal, P., Unutmaz, G., Kaya, D. \& Isik, A. T. Uric acid may be protective against cognitive impairment in older adults, but only in those without cardiovascular risk factors. Experimental Gerontology 89, 15-19 (2017).

4. Lu, N. et al. Gout and the risk of Alzheimer's disease: a population-based, BMl-matched cohort study. Annals of the Rheumatic Diseases 75, 547-551 (2016).

5. Latourte, A., Bardin, T. \& Richette, P. Uric acid and cognitive decline: a double-edge sword? Current Opinion in Rheumatology 30, 183-187 (2018).

6. Singh, J. A. \& Cleveland, J. D. Gout and dementia in the elderly: a cohort study of Medicare claims. BMC Geriatr 18, (2018).

7. Moorhouse, P. C., Grootveld, M., Halliwell, B., Quinlan, J. G. \& Gutteridge, J. M. Allopurinol and oxypurinol are hydroxyl radical scavengers. FEBS Lett 213, 23-28 (1987).

8. Fukui, T. et al. Effects of Febuxostat on Oxidative Stress. Clinical Therapeutics 37, 1396-1401 (2015).

9. Zhang, Q. et al. Allopurinol protects against ischemic insults in a mouse model of cortical microinfarction. Brain Research 1622, 361-367 (2015).

10. Maiwald, C. A. et al. Effect of allopurinol in addition to hypothermia treatment in neonates for hypoxic-ischemic brain injury on neurocognitive outcome (ALBINO): study protocol of a blinded randomized placebo-controlled parallel group multicenter trial for superiority (phase III). BMC Pediatr 19, 210 (2019).

11. Singh, J. A. \& Cleveland, J. D. Comparative effectiveness of allopurinol versus febuxostat for preventing incident dementia in older adults: a propensity-matched analysis. Arthritis Res. Ther. 20, 167 (2018).

12. Latourte, A. et al. Uric acid and incident dementia over 12 years of follow-up: a population-based cohort study. Ann. Rheum. Dis. 77, 328-335 (2018).

13. Scheepers, L. E. J. M. et al. Urate and risk of Alzheimer's disease and vascular dementia: A population-based study. Alzheimers Dement 15, 754-763 (2019).

14. Engel, B. et al. Hyperuricemia and dementia - a case-control study. BMC Neuro/ 18, (2018).

15. Erkinjuntti, T., Ostbye, T., Steenhuis, R. \& Hachinski, V. The effect of different diagnostic criteria on the prevalence of dementia. N. Engl. J. Med. 337, 1667-1674 (1997).

16. Vellas, B. et al. MAPT STUDY: A MULTIDOMAIN APPROACH FOR PREVENTING ALZHEIMER'S DISEASE: DESIGN AND BASELINE DATA. The Journal of Prevention of Alzheimer's Disease 1, 13-22 (2014).

17. Andrieu, S. et al. Effect of long-term omega 3 polyunsaturated fatty acid supplementation with or without multidomain intervention on cognitive function in elderly adults with memory complaints (MAPT): a randomised, placebo-controlled trial. Lancet Neurol 16, 377-389 (2017).

18. Slobodnick, A., Shah, B., Krasnokutsky, S. \& Pillinger, M. H. Update on colchicine, 2017. Rheumatology (Oxford) 57, i4-i11 (2018).

19. Johnson, R. J. et al. Uric acid and chronic kidney disease: which is chasing which? Nephrol Dial Transplant 28, 2221-2228 (2013).

20. Richette, P. et al. Improving cardiovascular and renal outcomes in gout: what should we target? Nat Rev Rheumatol 10, 654-661 (2014).

21. Sluijs, I. et al. A Mendelian randomization study of circulating uric acid and type 2 diabetes. Diabetes 64, 30283036 (2015).

22. Enomoto, A. et al. Molecular identification of a renal urate anion exchanger that regulates blood urate levels. Nature 417, 447-452 (2002).

23. Khosla, U. M. et al. Hyperuricemia induces endothelial dysfunction. Kidney Int 67, 1739-1742 (2005). 
24. Goicoechea, M. et al. Effect of allopurinol in chronic kidney disease progression and cardiovascular risk. Clin J Am Soc Nephrol 5, 1388-1393 (2010).

25. Khan, A. A., Quinn, T. J., Hewitt, J., Fan, Y. \& Dawson, J. Serum uric acid level and association with cognitive impairment and dementia: systematic review and meta-analysis. Age (Dordrecht, Netherlands) 38, 16 (2016).

26. Wishart, D. S. et al. DrugBank 5.0: a major update to the DrugBank database for 2018. Nucleic Acids Research 46, D1074-D1082 (2018).

27. Lagorce, D., Douguet, D., Miteva, M. A. \& Villoutreix, B. O. Computational analysis of calculated physicochemical and ADMET properties of protein-protein interaction inhibitors. Sci Rep 7, (2017).

28. Scherrmann, J. M. Drug delivery to brain via the blood-brain barrier. Vascular Pharmacology 38, 349-354 (2002).

29. Dawson, J., Quinn, T. J., Harrow, C., Lees, K. R. \& Walters, M. R. The effect of allopurinol on the cerebral vasculature of patients with subcortical stroke; a randomized trial. Br J Clin Pharmacol 68, 662-668 (2009).

30. Sonnen, J. A. et al. Pathological correlates of dementia in a longitudinal, population-based sample of aging. Ann Neurol 62, 406-413 (2007).

31. Burton, E. J. et al. Medial temporal lobe atrophy on MRI differentiates Alzheimer's disease from dementia with Lewy bodies and vascular cognitive impairment: a prospective study with pathological verification of diagnosis. Brain 132, 195-203 (2009).

32. Haglund, M., Passant, U., Sjöbeck, M., Ghebremedhin, E. \& Englund, E. Cerebral amyloid angiopathy and cortical microinfarcts as putative substrates of vascular dementia. Int J Geriatr Psychiatry 21, 681-687 (2006).

33. Gifford, K. A. et al. The source of cognitive complaints predicts diagnostic conversion differentially among nondemented older adults. Alzheimers Dement 10, 319-327 (2014).

34. Donohue, M. C. et al. The preclinical Alzheimer cognitive composite: measuring amyloid-related decline. JAMA Neurol 71, 961-970 (2014).

\section{Figures}

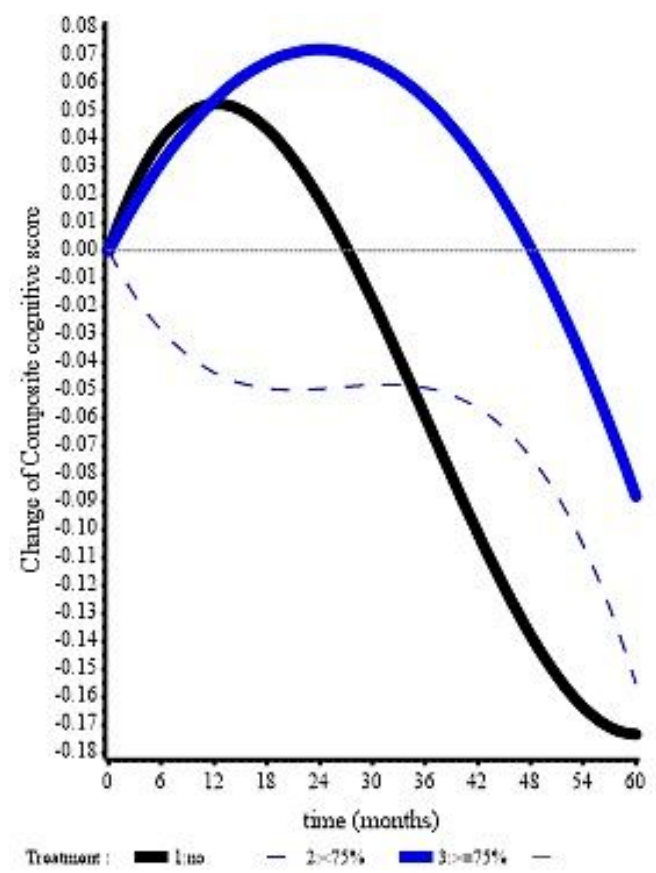

Figure 1 
Evolution of the cognitive composite score (Z-Score) in the PNT, PT $<75$ and PT $\geq 75$ groups during a 5-year follow-up, among the participants of the MAPT study. 